\title{
Six Commandments of Treatment Protocols During Covid-19 Pandemic in Dentistry
}

\author{
Agung Sosiawan $^{1^{*}}\left(\mathbb{D}\right.$, Dian Agustin Wahjuningrum ${ }^{(\mathbb{D})}$, Anuj Bhardwaj ${ }^{3,4}{ }^{(\mathbb{D})}$, Kratika

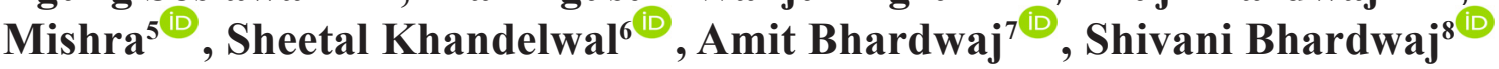

\begin{abstract}
${ }^{1}$ Department of Public Health, Faculty of Dental Medicine, Universitas Airlangga, Surabaya-Indonesia ${ }^{2}$ Department of Conservative Dentistry, Faculty of Dental Medicine, Universitas Airlangga, Surabaya-Indonesia ${ }^{3}$ Department of Conservative Dentistry and Endodontics, College of Dental Sciences, Rau, Indore. M.P.

${ }^{4}$ Adjunct Professor at Departement of Conservative Dentistry, Faculty of Dental Medicine, Airlangga University, Surabaya, Indonesia.

${ }^{5}$ Department Orthodontics and Dentofacial Orthopaedics, Modern Dental College and Research Centre, Indore, M.P. ${ }^{6}$ P. G. Resident, Department of Conservative Dentistry and Endodontics, College of Dental Sciences, Rau, Indore.M.P. ${ }^{7}$ Department of Orthodontics and Dentofacial Orthopaedics, Modern Dental College and Research Centre, Indore, M.P. ${ }^{8}$ Department of Prosthodontics, College of Dental Sciences, Rau, Indore. M.P., India
\end{abstract}

\section{A R T I C L E I N F O}

\section{Article history:}

Received 10 June 2021

Received in revised form 17 June 2021

Accepted 24 June 2021

Available online 30 June 2021

\section{Keywords:}

Angiotensin-converting enzyme 2

(ACE2) receptor,

Clinical Setup,

COVID-19,

Dental Clinic Management,

Infectious Disease.

\section{*) Corresponding author:}

agung-s@fkg.unair.ac.id

\begin{abstract}
A B S T R A C T
In December 2019, an outbreak in the city of Wuhan, Hubei China occurred and was named COVID- 19 by the World Health Organization and declared as a pandemic on January 30, 2020. The etiologic agent of acute respiratory disease is the novel corona virus 2019 (2019-nCoV) or the extreme acute respiratory syndrome corona virus 2 (SARS-CoV-2). During many dental operations, aerosols are produced and these aerosol methods, which are major problems for dentists, have become the main area of concern in dentistry. Dentists are at greatest risk since they are located close to the oropharynx. This study summarizes the effect of coronavirus disease 2019 (COVID-19) on dental care, administration, and emergency dental treatment service. It also identifies COVID-19 and explains about six commandments for dental practitioners during the treatment process to be practiced during the pandemic.
\end{abstract}

\section{Introduction}

The latest SARS-COV-2 corona-virus, a beta coronavirus, is the causative organism of Covid 19, an infectious disease. ${ }^{1}$ Due to the pneumonic disease outbreak, The Novel Coronavirus Disease 2019 (COVID-19), which originated in Wuhan, China, people are trapped around the globe. The COVID-19 outbreak was announced by the WHO as an international global health emergency on 30 January $2020 .^{2}$ On November 06, 2020, COVID-19 which is established in 213 countries, with a total of 47,930,397 confirmed cases and a death toll of $1,221,781$. With cases rising rapidly, it is of utmost importance to follow all necessary precautions and treatment protocol elaborated in this review explaining the guidelines for clinical setup in order to prevent further contamination and spread. The diameter of this enveloped strong vision RNA virus ranges from $60 \mathrm{~nm}$ to $140 \mathrm{~nm}$ with spiked surface projections giving it a crown-like form as the name suggests when examined under a microscope as coronavirus. ${ }^{3}$ There were HKU1, NL63, 229E and OC43 coronaviruses that been circulating in humans and usually cause serious respiratory disease. ${ }^{4,5}$ In reports, the baseline replication number (R0) of SARS-CoV-2 is documented to be approximately 2.25 or even higher (range from 1.4 to $6.5),{ }^{6}$ and family clusters of pneumonia ${ }^{7}$ occurrence lead to evidence of a quickly evolving human-to-human COVID-19 epidemic transmission. ${ }^{8}$ In dental clinics and hospitals which are (potentially infected by COVID-19), rigid and appropriate infection control protocols are urgently required. 
This paper provides the essential information regarding COVID-19 and infection in dental environments and better protection for dentists in affected areas of pandemics., ${ }^{9,10}$

Bats are suspected as a host of virus origin, and humans are infected by unidentified intermediate hosts. ${ }^{11}$ As tested by the analysis of virus genome sequencing, SARS-CoV-2 can be transferred from bats. To infect humans with SARS$\mathrm{CoV}-2$, angiotensin converting enzyme 3 (ACE2), the same receptor as SARS-CoV-2 may be used (Figure 1). ${ }^{8}$

The process of Coronavirus Disease-19 (COVID-19) transmission comes from the bats to the host intermediate which relates to the binding through Angiotensin Converting Enzyme-2 (ACE-2) to induce the complication of complication of the disease. It will be aggravated with comorbid disease. ${ }^{8}$

Genomic big data analytics that SARS-CoV-2 is phylogenetically related with extreme acute respiratory syndrome (SARS)-like bat viruses, so bats may be the possible primary reservoir. ${ }^{12}$ A major cause of human-tohuman transmission is direct contact with an infected person who is exposed to coughing, sneezing, respiratory droplets or aerosols. By inhalation, the absorption of particulates through the nose or mouth will reach the body's lungs. ${ }^{12-15}$

\section{Discussion}

\section{The Relationship between COVID-19 and Dentistry}

This SARS-CoV-2 is investigated in the saliva of infectious patients, suggesting that the aerosols released during dental medical treatment by an infected person may be highly contagious. In dental areas, the risk of cross-infection between dental professionals and patients can be high. These droplets can remain in the area even after the patient's operation, leading to contamination by dental professionals via contaminated surfaces. ${ }^{16-18}$ This virus can be found in aerosols up to 3 hours after surgery and can remain on surfaces for extended periods of time. For dental settings and hospitals that are (potentially infected by COVID-19), stringent and appropriate infection control procedures are urgently required. Covid-19 infection has been shown to spread through multiple routes that follow: (Table 1)

There might be large droplets with a diameter of $5 \mu \mathrm{m}$ or a diameter of $<5 \mu \mathrm{m}$. The larger droplets drop to the ground at a faster rate due to gravitational forces, and the smaller ones will remain trapped for a much longer period of time in the air and be ingested by a susceptible individual. ${ }^{20}$ During dental operations, it is difficult to minimize and reduce the output of droplets and aerosols to zero, so its transmission factor is of great importance in dental configurations. This virus can be found in aerosols and can survive on surfaces up to 3 hours after activity. (Figure 2)

COVID-19 can be transmitted from infected patient to the practice of dentistry in the two forms, such as: direct and indirect mode. Both of the transmission types related to droplet, aerosol, and droplet-aerosol's contaminating the surface of thing to the susceptible patient, dentistry, nurse, and the surrounding environment the practice of the dentist. ${ }^{18}$

\section{Six Commandments of Treatment Protocols by Dentist during COVID-19 Pandemic}

The six protocols followed for screening and management of Dental Emergencies. The first step is the protocols before patient enters the clinic. ${ }^{19-21}$ This step consists of: initial Tele-screening and Triaging, appointment scheduling and walk-in patient should be discouraged, check of signs and symptoms like respiratory illness i.e., cough, cold, fever by a Consent Form (proper questionnaire form format given to patients), and off the symptoms of the patient are similar to COVID-19, they should be admitted to be transfered to the nearest medical facility. ${ }^{22,23}$ After making sure that the patient has been selected using the first step, the second step is addressed to the reception area /waiting area protocol. In this area, the receptionists should advise patients to wash hands or sanitize hands with hand sanitizer based on alcohol and remove footwear outside the premises of the clinic. Provide the patient with a new facial mask and a foot cover. It is also important to check the temperature of the patient using a digital infrared thermometer and oxygen saturation using a pulse oximeter. In healthy individuals, $95 \%$ oxygen saturation is natural. $92 \%$ consider possible hypoxemia or deficiency in the body's oxygen-reaching tissues. Ensure that the consent and disclosure form should be undersigned by the patient. The receptionist also warns the patient about the minimum distancing of 3 feet between each patient in the waiting area to ensure social distancing. It should better to delete all the books from the reception room, magazines, flower vases. There should be a show of proper hand hygiene guidelines in the reception room. Computer screens and keyboards should be covered with a lightweight, clear barrier that can be dispatched of and modified between patients (e.g. plastic wrap).

The third step is addressed when the patient in the dental operatory protocol. The dental surgeon must use PPE and N-95 facial mask along with face shield. The circulation of airflow must be improved by having extra ventilation to enable a minimum of 6ACH (Air Changes every Hour). Use an operational standalone HEPA 13, HEPA 14 air filter. Usage of exhaust fans to remove air that is polluted. And the use, where available, of ventilation systems. With a moderate rubber tube attached to the dental operating microscope, the polycarbonate shield can be positioned to create an airflow of $3.9 \mathrm{ft} / \mathrm{min}$ at a position near to the patient's oropharynx. For this reason, a 4-inch flexible ducting system (Part A1-DTA4, AC Infinity Inc) can be developed and mounted to the Powertec 4-inch inlet flange (Part 70126, Powertec Inc) with a 4-inch metal worm gear clamp (supplied with aluminum tubing) on a polycarbonate disk (as shown in Figure 3). ${ }^{23,24}$

Before examining the patient, patient is advised to rinse his mouth using Povidone Iodine 0.2 percent or 1 percent hydrogen peroxide along with extra-oral face scrubbing. ${ }^{18}$ The dentist must cover the patient's mouth using Rubber dam and high-volume suction in cases of aerosol generating procedures. It is recommended to sterilized the handpieces after being used each patient. For heat sensitive semi-critical instruments, 2 percent Glutaraldehyde may be used. ${ }^{22,23}$ Using one water supplemented by a detergent assisted by a low-level disinfectant, such as $3 \%$ hydrogen peroxide, $1 \%$ sodium hypochlorite, or wet-mopping approved EPA agents. ${ }^{22,23}$

The fourth step is done after the treatment protocols, which consists of: advising the patient to rinse his mouth with 0.2 percent or 1 percent hydrogen peroxide using Povidone Iodine again and remasking their face before leaving the operation. It is preferred to use electronic forms of payment and automated references to care procedures. Using alcohol based hand rub to allow patients to sanitize before leaving the clinic. If the patient shoud be appointed again for the other days, they should be done using the fifth 
step. The fifth step consists of next patient's appointment that can be done by using a minimum of 6 air changes per hour, dental operations should be well ventilated. Using natural ventilation for 60 minutes or hydrogen peroxide vapor defogging disinfectants for 30-45 minutes. As a disinfection technique, it is also possible to use HEPA Air filters minimum $12 \mathrm{ACH}$ for 20 minutes and Ultra-violet Germicidal Irradiation and Ventilation i.e., minimum 6ACH for 15 minutes. ${ }^{24}$ The floor wet mopping can be done again.
The health protocol to finish the dental practice is addressed for the sixth step, which consists of: PSA and N-95 mask doffing and 3-ply surgical mask doffing in a separate region. Medical waste management should be shipped in properly sealed ligated medical waste container bags in a double layered yellow color, which should be labelled and disposed of in compliance with the 2016, 2018 biomedical waste management and handling regulations. ${ }^{25,26}$

Table 1. Routes of Transmission

\begin{tabular}{|c|c|c|c|c|c|}
\hline Direct Transmission & Indirect Transmission & $\begin{array}{c}\text { Airborne } \\
\text { Transmission }\end{array}$ & $\begin{array}{c}\text { Droplet }(>5 \mu \mathrm{m} \text { in } \\
\text { diameter) }\end{array}$ & $\begin{array}{c}\text { Aerosol }(<5 \mu \mathrm{m} \text { in } \\
\text { diameter })\end{array}$ & Self Inoculation \\
\hline $\begin{array}{l}\text { Transmission, } \\
\text { through direct con- } \\
\text { tact, between an in- } \\
\text { fected person and a } \\
\text { cleansed individual. }\end{array}$ & $\begin{array}{l}\text { It is via a fomite } 20-a \\
\text { contaminated object by } \\
\text { an infected person that } \\
\text { can transmit infection } \\
\text { to someone else. }\end{array}$ & $\begin{array}{l}\text { Contains of } \\
\text { droplet, aero- } \\
\text { sol, and self } \\
\text { inoculation }\end{array}$ & $\begin{array}{l}\text { Droplets that } \\
\text { are spread can } \\
\text { be ingested by } \\
\text { other suscepti- } \\
\text { ble individuals } \\
\text { while sneezing or } \\
\text { coughing. As they } \\
\text { are larger in size } \\
\text { and drop on sur- } \\
\text { faces, the surface } \\
\text { is also contami- } \\
\text { nated. }\end{array}$ & $\begin{array}{l}\text { Thus, smaller in size } \\
\text { remains for a longer } \\
\text { period of time in the } \\
\text { air and can be in- } \\
\text { haled by a suscepti- } \\
\text { ble person. }\end{array}$ & $\begin{array}{l}\text { Self-inoculation } \\
\text { occurs through bad } \\
\text { labels that control } \\
\text { disease. }\end{array}$ \\
\hline
\end{tabular}

DIRECT TRANSMISSION Transmission, through direct contact, between an infected person and a cleansed individual.

INDIRECT TRANSMISSION It is via a fomite 20 - a contaminated object by an infected person that can transmit infection
to someone else.

\begin{tabular}{ll}
\hline AIRBORNE TRANSMISSION & Contains of droplet, aerosol, and self inoculation \\
\hline DROPLET $(>5 \mu \mathrm{m}$ in diameter) & $\begin{array}{l}\text { Droplets that are spread can be ingested by other susceptible individuals while sneezing or } \\
\text { coughing. As they are larger in size and drop on surfaces, the surface is also contaminated. }\end{array}$ \\
\hline AEROSOL $(<5 \mu \mathrm{m}$ in diameter) & $\begin{array}{l}\text { Thus, smaller in size remains for a longer period of time in the air and can be inhaled by a } \\
\text { susceptible person. }\end{array}$ \\
\hline
\end{tabular}

SELF-INOCULATION Self-inoculation occurs through bad labels that control disease.

This table was adapted from 19, 20, 21

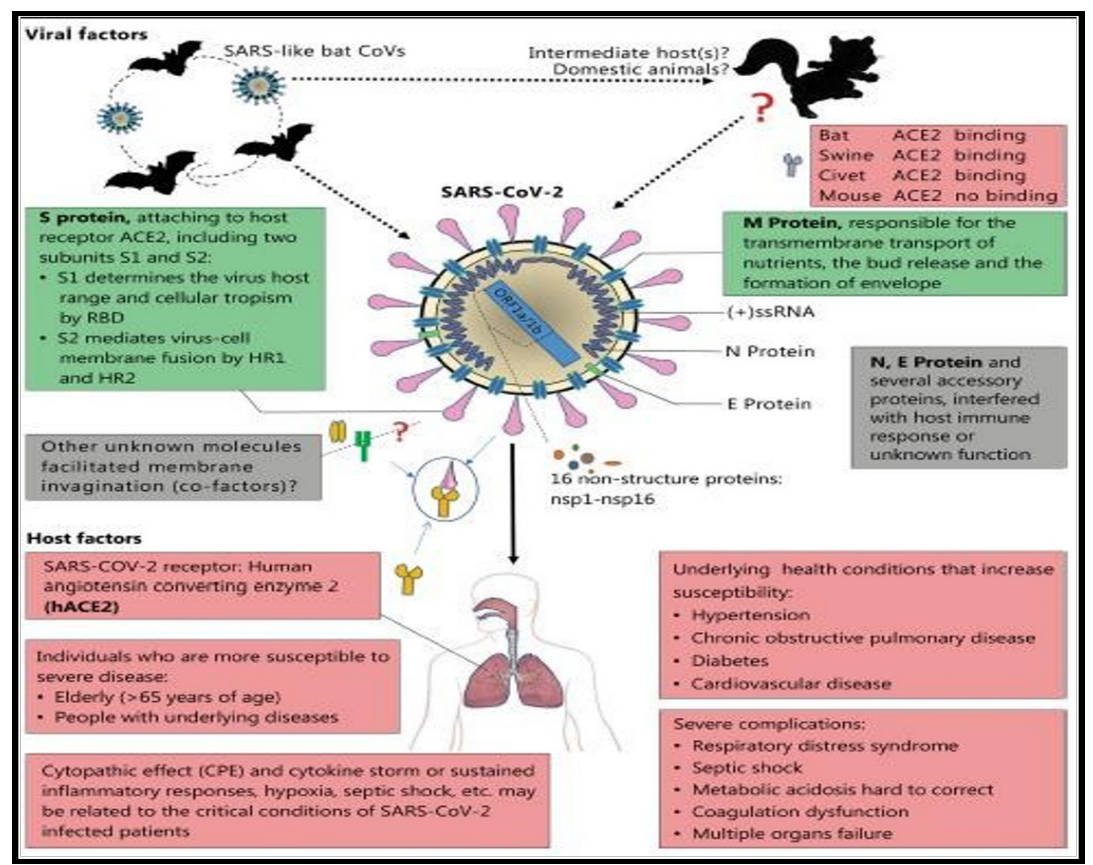

Figure 1. Pathogenesis of SARS-CoV-2 ${ }^{8}$ 


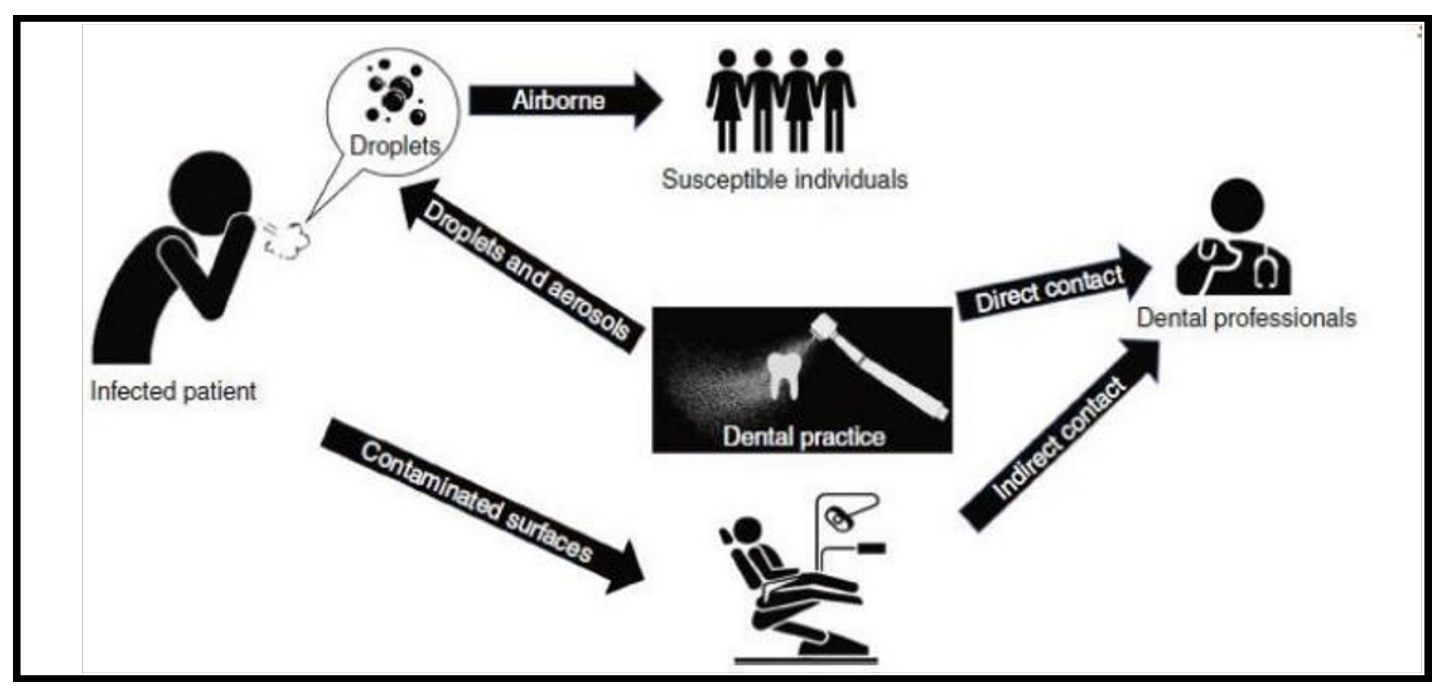

Figure 2. showing different routes of transmission in dental clinics and hospitals ${ }^{20}$

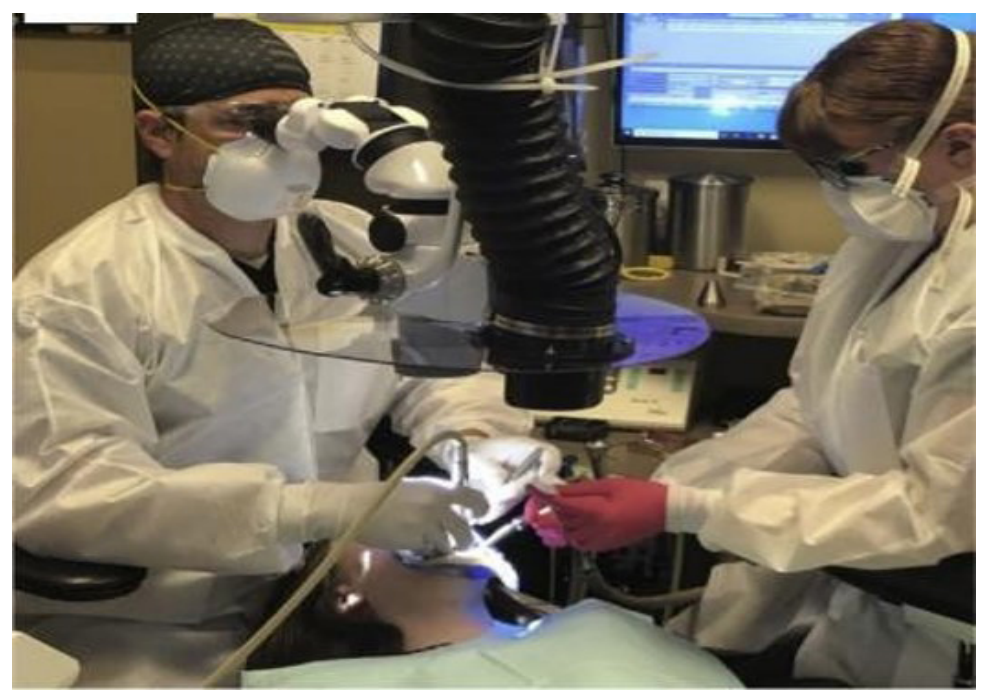

Figure 3. The setup of the evacuation system using polycarbonate disc and evacuation system ${ }^{23}$

\section{Conclusion}

The pandemic of Covid-19 has absolutely changed the condition of dental health care practitioners and the way they operate. In order to protect the whole population and themselves from the possibility of serious infectious pandemics, dental teams and practitioners should obey and follow all the latest protocols. Patients with Covid-19 symptoms requiring urgent dental care can be approached using Tele-dentistry, an audio and video input system that collects medical information and interacts with patients. It is cost-effective and can relieve the patient from severe pandemic pain and anxiety. With the virus emerging every single day the development of the disease is altered. In order to suppress the virus, recent research is taking place around the globe and preventive and therapeutic steps are increasingly evolving. Prevention is of utmost importance in dental practice to avoid virus transmission and prevent dental clinics from being a center for viral spread until the exact virology is known. More research is needed to better identify the exact mechanism of action of the corona virus and to assist in the production of vaccines specific to antidotes and viruses. Ever changing statistics represents the limitation of this review.

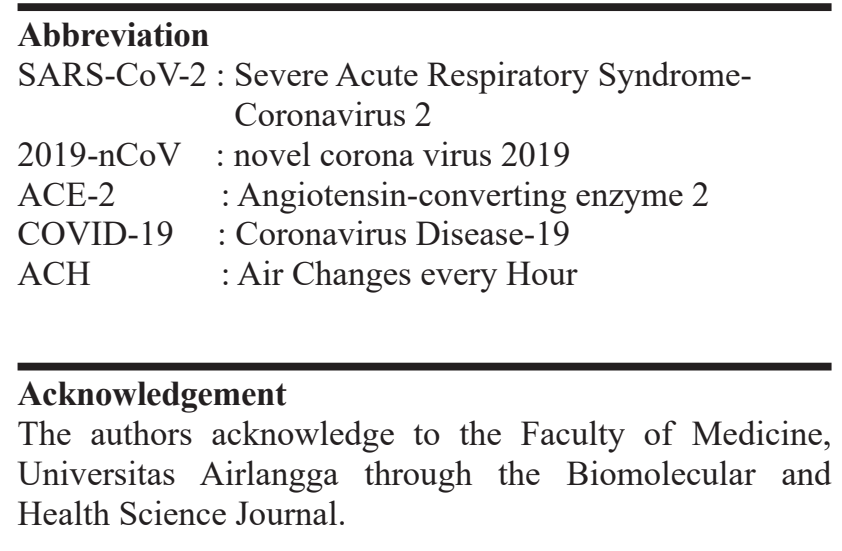

\section{Conflict of Interest}

The author stated that there is no conflict of interest in publishing this article. 


\section{References}

1. Ferretti L, Wymant C, Kendall M, Zhao L, Nurtay A, Abeler-Dörner L, et al. Quantifying SARS-CoV-2 transmission suggests epidemic control with digital contact tracing. Science. 2020;8:368.

2. Mahase, E. China coronavirus: WHO declares international emergency as death toll exceeds 200. BMJ. 2020;368:m408.

3. Richman DD, Whitley RJ, Hayden FG. 2016. Clinical Virology, 4th ed pp 119-25 ASM Press: Washington

4. Singhal T. A review of coronavirus disease-2019 (COVID-19). The Indian Journal of Pediatrics. 2020;13:1-6.

5. Riou J, Althaus CL. Pattern of early human-to- human transmission of Wuhan 2019 novel coronavirus (2019 nCoV), December 2019 to January 2020. Euro Surveill. 2020; 25(4): 2000058

6. Ying L, Gayle Albert A, Annelies WS, Joacim R. The reproductive number of COVID 19 is higher compared to SARS coronavirus. J Travel Med. 2020. 13;27(2):taaa021.

7. Chan JF, Yuan S, Kok KH, To KK, Chu H, Yang J et al. A familial cluster of pneumonia associated with the 2019 novel coronavirus indicating person-to-person transmission: a study of a family cluster. The Lancet. 2020;395:514-23

8. Guo YR, Cao QD, Hong ZS, Tan YY, Chen SD, Jin HJ et al. The origin, transmission and clinical therapies on coronavirus disease 2019 (COVID-19) outbreak an update on the status. Military Medical Research. 2020;7(1):1-0.

9. Adhikari SP, Meng S, Wu YJ, Mao YP, Ye RX, Wang QZ, et al. Epidemiology, causes, clinical manifestation and diagnosis, prevention and control of coronavirus disease (COVID-19) during the early outbreak period: a scoping review. Infectious diseases of poverty. $2020 ; 9(1): 1-2$

10. Meng L, Hua F, Bian Z. Coronavirus disease 2019 (COVID-19): emerging and future challenges for dental and oral medicine. Journal of Dental Research. 2020; 99(5): 481-7.

11. Zhou P, Yang XL, Wang XG, Hu B, Zhang L, Zhang W, et al. A pneumonia outbreak associated with a new coronavirus of probable bat origin. Nature. 2020;579:270-3

12. Lu R, Zhao X, Li J, Niu P, Yang B, Wu H, et al. Genomic characterization and epidemiology of 2019 novel coronavirus: implications for virus origins and receptor binding. The Lancet. 2020;395:565-574

13. Phan LT, Nguyen TV, Luong QC, Nguyen TV, Nguyen HT, Le HQ, et al. Importation and human-to-human transmission of a novel coronavirus in Vietnam. N Engl J Med. 2020; 382(9):872-874.
14. Parry J. China coronavirus: cases surge as official admits human to human transmission. British Medical Journal. 2020;368:m236

15. Li Q, Guan X, Wu P, Wang X, Zhou L, Tong Y, et al. Early transmission dynamics in Wuhan, China, of novel coronavirusinfected pneumonia. N Engl J Med. 2020;382:1199-1207.

16. K. K. To, O. T. Tsang, C. Chik-Yan Yip et al., "Consistent detection of 2019 novel coronavirus in saliva," Clinical Infectious Diseases. 2020;71(15):841-843.

17. X. Peng, X. Xu, Y. Li, L. Cheng, X. Zhou, and B. Ren. Transmission routes of 2019-nCoV and controls in dental practice. International Journal of Oral Science. 2020;12:9

18. J. Wei and Y. Li. Airborne spread of infectious agents in the indoor environment. American Journal of Infection Control. 2016;44(9):102108

19. J. S. Kutter, M. I. Spronken, P. L. Fraaij, R. A. Fouchier, and S. Herfst. Transmission routes of respiratory viruses among humans. Current Opinion in Virology. 2018;28:142-151

20. Huang C, Wang Y, Li X, Ren L, Zhao J, Hu Y, et al. Clinical features of patients infected with 2019 novel coronavirus in Wuhan, China. Lancet. 2020;395(10223):497-506.

21. To KK-W, Tsang OTY, Chik-Yan Yip C, Chan K-H, Wu T-C, Chan J, et al. Consistent detection of 2019 novel coronavirus in saliva. Clin Infect Dis. 2020; 71(15):841-843

22. Kratika Mishra, Amit Bhardwaj, Vaibhav Misra, Anuj Bhardwaj, Shivani Bhardwaj, Shobhana Misra Novel COVID-19 - Origin, Emerging Challenges, Recent Trends, Transmission Routes and Control - A Review. J Contemp Orthod. 2020;4 (1): 57-67.

23. Russell C. Development of a Device to Reduce Oropharyngeal Aerosol Transmission. J Endod. 2020; 46(8): 1144-8 Available online 7 June 2020 from https://doi.org/10.1016/j.joen.2020.05.012

24. Standard Operating Protocol (SOP) for dental patients during covid 19 pandemic V.Gopi Krishna, Krithika Datta, Ruchika R Nawal, Kurunji Amlavaty.SOP.COVID.2020.Version.1

25. Madjid M, Safavi-Naeini P, Solomon SD, Vardeny O. Potential effects of Coronaviruses on the cardiovascular system: a review. JAMA Cardiol. 2020; 5(7): 831-40 Available online 27 March 2020 https://doi.org/10.1001/jamacardio.2020.1286

26. Macapagal J. Applications of Teledentistry during the COVID-19 Pandemic Outbreak. Applied Medical Informatics. 2020 Sep 29;42(3):133-41. 